\title{
The sauna - revisited
}

\section{L.F.J (Jo) Hermans and Timo Vesala}

Tn Europhysics News 37/6 (2006) we addressed several aspects of the funny situation in which we find ourselves when visiting the sauna. One question remained a bit open: What exactly causes the temporary heat pulse that we feel when we throw some water on the hot stones, thereby temporarily elevating the air humidity? All we could produce at the time was the 'educated guess' that at least four different contributions could play a role. But that did not really solve the question satisfactorily. Fortunately, Timo Vesala, professor of Meteorology at the University of Helsinki, came to the rescue. Having done qualitative observations during a few years in his own sauna twice a week, he solved this non-trivial problem and published a paper on the issue [1]).

Here is the surprise: The latent heat released in the condensation of water vapour onto the skin is an important mechanism - perhaps the most important one. The reason is that our skin is most probably the coldest place in the sauna, and the humidity can easily become $100 \%$ near the skin.

That's beautiful! We are used to think in terms of evaporation from our skin, not condensation. But the sauna is something special, and we should think beyond the conservative.

To check the validity of the argument, let us assume the sauna temperature to be $100^{\circ} \mathrm{C}$, (real Finnish sauna's are somewhere between 80 and $110^{\circ} \mathrm{C}$ ). This eases the analysis since $100 \%$ humidity nicely corresponds to $1000 \mathrm{mbar}$. What happens can now be easily seen from the vapour pressure curve,

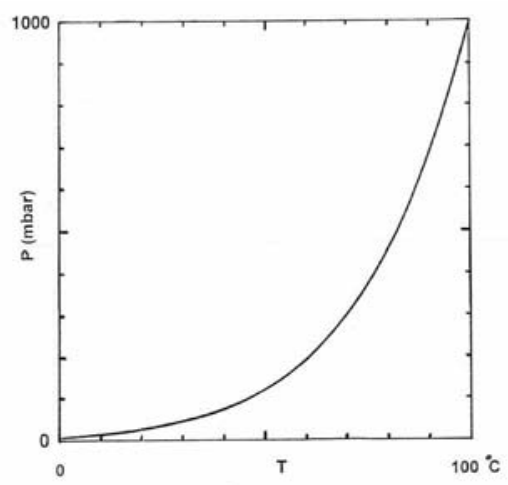
reproduced here for convenience. As pointed out in the previous sauna item (and readily checked from the curve), the humidity will automatically be $3 \%$ at most if the outside air is heated to sauna temperature. This will go up if extra $\mathrm{H}_{2} \mathrm{O}$ is released, for example by perspiration.

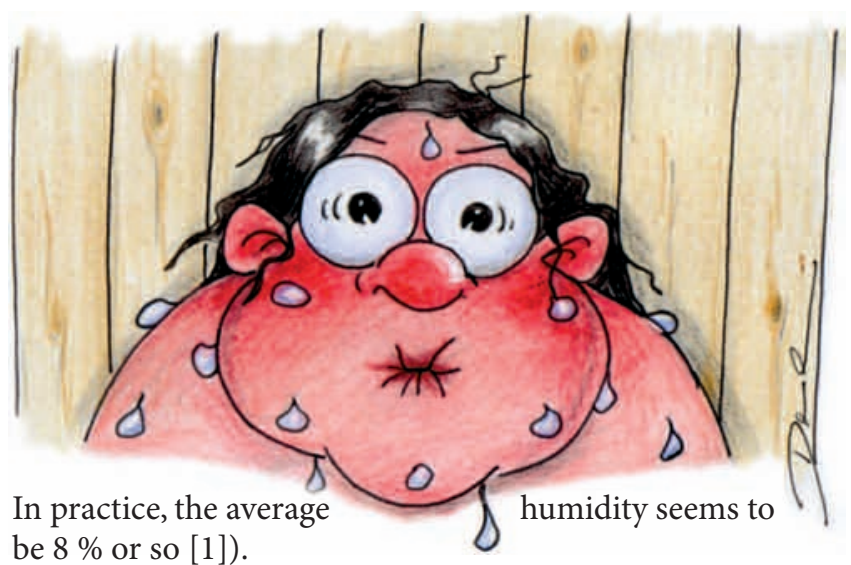
be $8 \%$ or so [1]).

From the water vapour pressure curve we see that $8 \%$ humidity (i.e., 80 mbar in this case) will lead to saturation at about $40^{\circ} \mathrm{C}$. This is almost exactly the sauna-warmed temperature of our skin: $43^{\circ} \mathrm{C}$ [1]), as confirmed by infrared skin-temperature observations of female students during the field course on micrometeorology at Hyytiälä Forestry Field Station (unpublished data). In other words: if the humidity is raised a bit, to $10 \%$ for example, condensation onto our skin will be inevitable. And this is precisely what happens when we throw water on the hot stones.

One of us (T.V.) has also done a quantitative analysis to assess the extent to which condensation contributes to the heat pulse. He finds that this latent heat flux is around $4 \mathrm{~kW}$. This is on the same order of magnitude as the ordinary heat flux, which is already enhanced during the heat pulse by the extra convection (the analysis does not include heat exchange by radiation between the body and the hot oven).

So: next time you're in the sauna, you may want to check the perspiration experiment.

But if you prefer to just sit and relax: no sweat..

\section{References}

[1] T. Vesala: Phase transitions in Finnish sauna. In: Nucleation and Atmospheric Aerosols. Proceedings of the Fourteenth International Conference on Nucleation and Atmospheric Aerosols, Eds. M. Kulmala and P.E. Wagner, 403-406. Pergamon, 1996. 